\title{
KINEMATIC WAVE モデルの集中化 Lumping of the Kinematic Wave Model
}

$\begin{array}{llllll}\text { 京都大学工学部 } & \text { 正員 } & \text { 高 } & \text { 棹 } & \text { 㻟 } \\ \text { 京都大学工学部 } & \text { 正員 } & \text { 椎 } & \text { 葉 } & \text { 充 } & \text { 晴 } \\ \text { 京都大学大学院 } & \text { 学生員 } & \text { 中 } & \text { 北 } & \text { 英 } & \text { 一 } \\ \text { 京都大学大学院 } & \text { 学生員 } & \text { 張 } & \text { 昇 } & \text { 平 }\end{array}$

1.はじめに

流出現象は空間的広がりの中で生起する現象である。眝留関数法などの集中型モデルは空間的広がりを無 視したモデルであり，それを無視できない場合，複数個の集中型モデルを連結したモデルを考える必要があ る。こうした集中型モデルの「分布化」は，取扱いの容易さをある程度保持しながら分布系ししての流出系 の特性を考虑するものであるが，分布化の基準は必ずしも明確でない。

本研究では，むしろ分布型モデルである kinematic wave モデルを出発点とし，「集中化」の方法と集中 化誤差構造を議論し，集中化の基準を与える。すなわち，場を有限個の眝水池系に分割し，定常時水面形状 を積分して得られる各眝水池の眝水量〜流出量関係式を適用して, kinematic wave モデルを多段眝水池モ デルで近似（集中化）する。さらに，その集中化誤差と，場・入力の条件および集中化の程度との関係を明 らかにして，集中化の基準を明確にする。

2. 単一要素 kinematic wave モデルの集中化

本章では, 単一要素 kinematic wave モデル

$$
\partial \mathrm{h} / \partial \mathrm{t}+\partial \mathrm{q} / \partial \mathrm{x}=\mathrm{r}(\mathrm{t}), \quad \mathrm{q}=\alpha \mathrm{h}^{\mathrm{m}}, \quad 0 \leqq \mathrm{x} \leqq \mathrm{L}
$$

を考察する。ただし， $\alpha, m, L$ は定数， $\mathrm{t}$ は時刻， $\mathrm{x}$ は位置， $\mathrm{r}(\mathrm{t})$ は時刻 $\mathrm{t}$ の降雨強度, $\mathrm{h}, \mathrm{q}$ は水深， 流量である。

2.1 単一要素 kinematic wave モデルの無次元化と多段貯水池モデルによる集中化

降雨継続時間を $t_{r}$, 平均降雨強度を $\overline{\mathrm{r}}$ とし，

$$
\begin{array}{lll}
t_{c}=\left(L /\left(\alpha \bar{r}^{m-1}\right)\right)^{1 / m}, \quad T=t / t_{c}, & X=x / L, \quad H=h /\left(\bar{r} t_{c}\right), \quad Q=q /(r L), \\
T_{R}=t_{r} / t_{c}, & R(T)=r\left(t_{c} T\right) / \bar{r}, & P(\tau)=r\left(t_{r} \tau\right) / \bar{r}
\end{array}
$$

とおくと，(1)式は

$$
\partial H / \partial T+\partial Q / \partial X=R(T)=P\left(T / T_{R}\right), \quad Q=H^{m}, \quad 0 \leqq X \leqq 1
$$

と無次元化される。 $T_{R}$ は, 系の応答時間の代表値 $t_{c}$ に相対的な入力の継続時間を表し，P $(\tau)$ は入力の時間 配分パターンを表す。

無次元化式（3）に対し，

$$
0=X_{0, k}<X_{1, k}<\cdots<X_{k, k}=1
$$

なる分点 $X_{i}, k, i=0,1, \ldots, K$ をとって，区間 $\left(X_{i-1}, k\right.$, $\left.X_{i}, k\right)$ での $H$ の積分值を $S_{i}, X_{i}, k$ での $H, Q$ を $H_{i}$, $Q_{i}$ と表して, $F_{i, k}=X_{i, k}-X_{i-1, k}$ (図 1 参照),

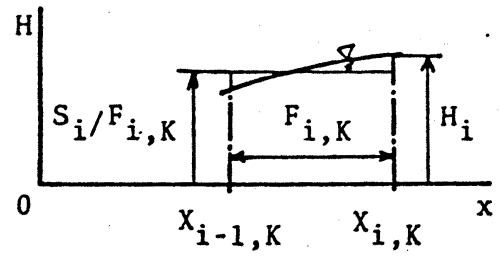

図 1 記号の説明 
とおくと，

$$
\begin{aligned}
& Q_{i}=H_{i}{ }^{m}, \\
& \mathrm{dS}_{i} / d T=F_{i}, k R(T)+Q_{i-1}-Q_{i}, \quad Q_{0}=0
\end{aligned}
$$

を得る。 $H_{i}$ が $S_{i}$ の関数であればこの式で kinematic wave モデルを集中化できることになる。一般には， $H_{i}$ は $S_{i}$ の関数として一意的に定まらないが，定常時には H $\propto X^{1 / m て ゙ あ る か ら, ~}$

$$
\begin{aligned}
& H_{i}=b_{i} \cdot S_{i} / F_{i}, k \\
& b_{i}=a X_{i}, k^{1 / m} F_{i, k} /\left(X_{i}, k^{a}-X_{i-1}, k^{a}\right)
\end{aligned}
$$

なる関係がある。ただし， $a=(m+1) / m$ とおいた。 $b_{i}$ は, 各区間内平均貯水深 $S_{i} / F_{i}, k$ に対する区間下流端 水深の比を表す。

入力 $\mathrm{R}(\mathrm{T})$ の変化が緩やか, すなわち， $\mathrm{T}_{\mathrm{R}}$ が大きい ときは，水面形状淀常時のそれで近似できるので，(5) 式を(4)式に代入した多段眝水池（reservoir cascade）

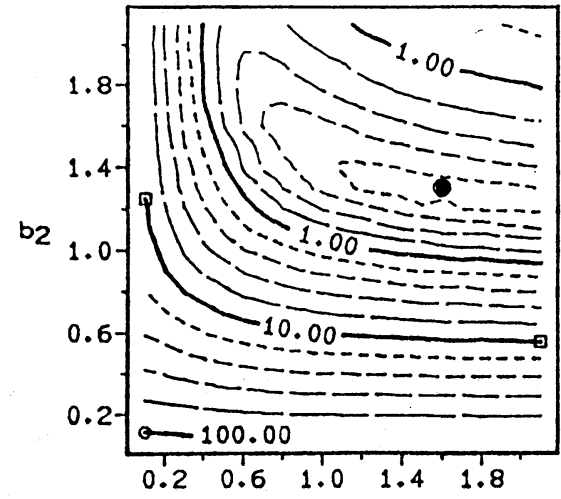

$b_{1}$

図 2 眝水池個数が 2 の多段眝水池 モデルの誤差自乗和の等檤線 モデルで kinematic wave モデルが集中化される。

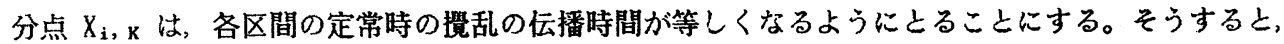
$X_{i, k}$ は,

$$
X_{i, k}=(i / K)^{m}
$$

によって定められる。 $b_{i}$ を決定する公式 $(5 \mathrm{~b})$ が適切であることを確認するために， $\mathrm{T}_{\mathrm{R}}$ が 5 の二等辺三角 形状の入力に対して， $b_{1} ， b_{2}$ を種々変化させたときの多段貯水池モデルによる流出量を $\Delta \mathrm{t}=0.05$ 間隔 で $\mathrm{T}=2 \cdot \mathrm{T}_{\mathrm{R}}$ まで求め, kinematic wave モデルによる值との差の自乗和を計算した結果を図 2 に示す。 ただし， $m=5 / 3$ とした。公式(5b)による值（図中，黑丸で示す）が適切であることをこの図から読み取る ことができる。

\section{2 集中化鿁差の構造}

非線形指数 $\mathrm{m}$ ，降雨配分パターン $\mathrm{P}(\tau)$ を固定すると，集中化誤差構造を支配するのは，系の応答時間 の代表值 $t_{c}$ に相対的な入力の継続時間 $\mathrm{T}_{R}$ である。

$\mathrm{T}_{\mathrm{R}}$ が小さくなると, $\mathrm{R}(\mathrm{T})=\mathrm{P}\left(\mathrm{T} / \mathrm{T}_{\mathrm{R}}\right)$ の時間的変化は急激になり，その変化を記憶するために状態量（= 区間貯水量 $S_{i}$ ）の個数 K を増やす必要がある。実際，降雨配分パ夕ーンを 2 等辺 3 角形状として計算を すると， $T_{R}$ が大きいときは $K=1$ でも集中化愦差は小さく（図 $3 a ） ， T_{R}$ が小さくなると $K=1$ では 集中化誤差が大きくなり（図 $3 \mathrm{~b}$ )，誤差を図 $3 \mathrm{a}$ と同程度にするためには $\mathrm{K}=5$ にしなければならない

(図 3 c) 。ただし，kinematic wave モデル，多段眝水池モデルによる流出量を $Q_{K}(T) ， Q_{R}(T)$ とすると き, 集中化誤差を,

$$
\mathrm{e}=\max _{\mathrm{T} \leqq \mathrm{T}_{\mathrm{E}}}\left\{\left|Q_{\mathrm{K}}(\mathrm{T})-\theta_{\mathrm{R}}(\mathrm{T})\right| /\left\{Q_{\mathrm{K}}(\mathrm{T})+\max _{\mathrm{T}} \mathrm{T}_{\mathrm{E}} Q_{\mathrm{K}}(\mathrm{T})\right\}\right\}
$$

（ $T_{E}$ は $Q_{K}(T)$ の累加が流入量の98\%となる時刻）で評価するものとする。

図3には, kinematic wave モデル，多段貯水池モデルによる系全体での貯水量〜流出量関係も示してい る。 $\mathrm{T}_{\mathrm{R}}$ が大きいときは $\mathrm{K}=1$ でもほぼ貯水量〜流出量関係を表し得るが， $\mathrm{T}_{\mathrm{R}}$ が小さくなると，K=1 では眝水量〜流出量のループに追随できず貯水量〜流出量のループを表すために貯水池の個数 K を增やさ 

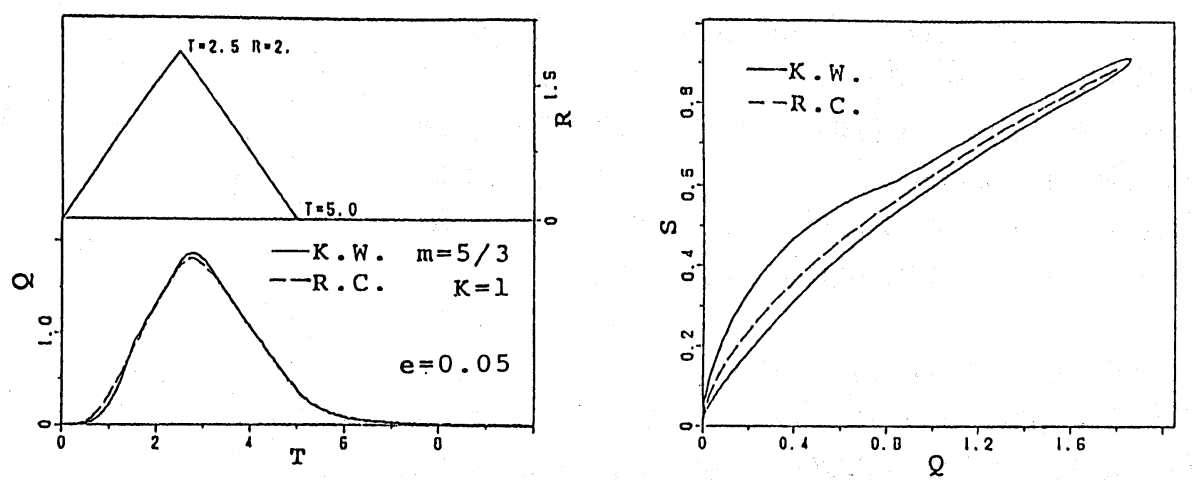

a. $T_{R}=5, \quad K=1$ の場合
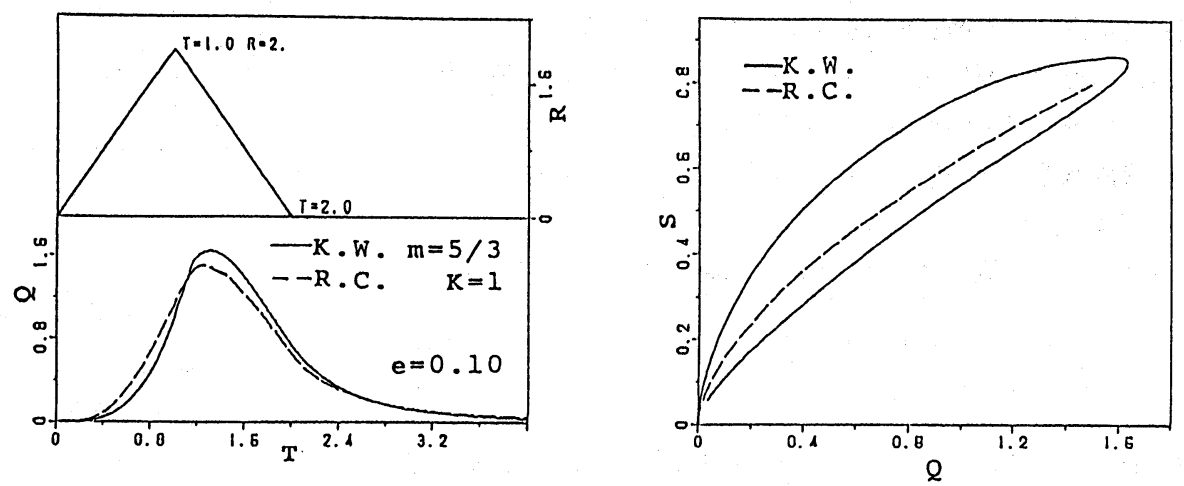

b. $\quad T_{R}=2, K=1$ の場合
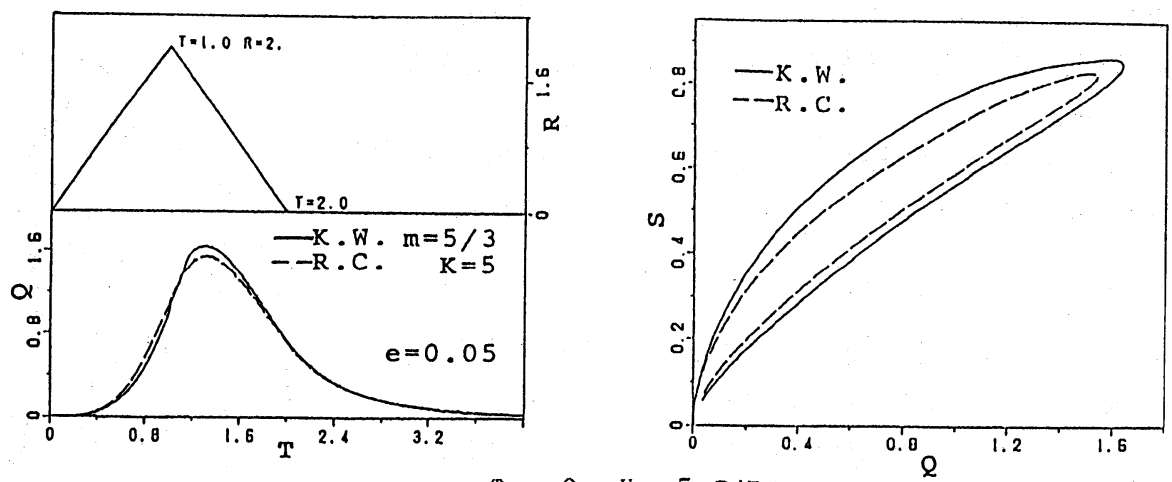

c. $\mathrm{T}_{\mathrm{R}}=2, \mathrm{~K}=5$ の場合

図 3 多段貯水池（R.C.）モデルと kinematic wave ( K.W. )モデルの比較

（左側は流出量の，右側は貯水量～流出量関係の比較）

ねばならなくなるのである。

降雨配分パターンを 2 等边 3 角形状とし， $m=5 / 3$ としたときの集中化誤差 e の等值線図が図 4 である。 また，最小自乗法によって求めた集中化誤差 e の近似式は

$$
\mathrm{e}=0.184 /\left(\mathrm{T}_{\mathrm{R}}{ }^{0.180} \mathrm{~K}^{0.452}\right)
$$

である。いま，斜面流を単一要素 kinematic wave モデルで取り扱うものとし，その等価粗度係数 N，勾配 
$\theta$, 斜面長 $\mathrm{L}$, 平均降雨強度 $\overline{\mathrm{r}}$, 降雨継続時間 $\mathrm{t}_{\mathrm{r}}$ が与えられてい るものとすると, $\alpha=\sqrt{\sin \theta} / \mathrm{N}, m=5 / 3$ として(2)式から $\mathrm{T}_{\mathrm{R}}$ が 求められるので，図 4 または(8)式を利用すると所要の精度 eに対 する貯水池個数 $K$ を求めることができる。 $\bar{r} ， t_{r}$ の增大とともに $\mathrm{T}_{\mathrm{R}}$ は增加するから, 標準入力に対して $\mathrm{K}$ を定めておけば，規模 の大きい入力に対しても精度は保証されることになる。

\section{3. 河道網系 kinematic wave モデルの集中化}

本章では，河道網系 kinematic wave モデルの集中化の方法とそ の基準を与える。すなわち, 河道網を有限個の部分河道網に分割し, 定常時水面形状から得られる各部分河道網の貯水量 流出量関係式 を適用して河道網系を連立常微分方程式系でモデル化する。さらに， 前章て議論した単一要素 kinematic wave モデルの集中化誤差構造 と関連させて部分河道網への分割基準を与える。

3.1 多段貯水池モデルによる河道網系 kinematic wave モデルの集中化

各河道リンク内の流れは, kinematic wave モデル

$$
\begin{aligned}
& \partial A / \partial t+\partial Q / \partial x_{i}=q_{i} \\
& Q=\alpha_{i} A^{m}
\end{aligned}
$$

で記述されるとする。ただし， $\mathrm{x}_{\mathbf{i}}$ は河道リンク i (以下，河道リ ンクの番号を英小文字で，部分河道網の番号を英大文字で表す）の 上流端点からの距離，A，日 はそれぞれ流積, 流量, $q_{i}$ は河道の 流れ方向単位幅当たり侧方流入強度， $\alpha_{\mathrm{i}}, \mathrm{m}$ は kinematic 定数で ある(図 5 参照)。

基礎方程式 (1)を各部分河道網ごとに空間座標について積分する と, 部分河道網 $J$ の眝水量 $S_{J}(t)$ に関する連立常微分方程式

$$
d S_{J}(t) / d t=\sum Q_{I}(t)-Q_{J}(t)+q_{J}(t), J=1, \ldots, N
$$

が得られる。 $Q_{J}(t)$ は部分河道網 $J$ の流出量で， $\sum$ は部分河道 網 J への流入となるすべての部分河道網 I についての和を表す。 $\mathrm{q}_{J}(\mathrm{t})$ は部分河道網 $\mathrm{J}$ への側方流入量, $\mathrm{N}$ は部分河道網の個数て ある。(10)式右辺の $Q_{J}(t)$ を $S_{J}(t)$ の一価関数として表現でき れば，(10)式右辺にその関数を代入することによって河道網系 kinematic wave モデルを集中化できることになる。

側方流入強度や上流部分河道網からの流入強度の時間的変化が緩 慢であれば，水面形状を定常時のそれで近似することができる。そ こで，集水域単位面積当たりの流出強度 $\mathrm{r}_{0}$ を一定として流れが定 常になったときの水面形状を考えて， $Q_{J}(t)$ と $S_{J}(t)$ の関係を求 める。

河道リンク $\mathrm{i}$ の長さを $\ell_{i}$, その集水面積を $\mathrm{f}_{\mathrm{i}}$ とすれば, 侧 方流入強度は $\mathrm{q}_{i}=\mathrm{r}_{0} \cdot \mathrm{f}_{\mathrm{i}} / \ell_{\mathrm{i}}$ となり, 河道リンク $\mathrm{i}$ の眝水量 $S_{i}$

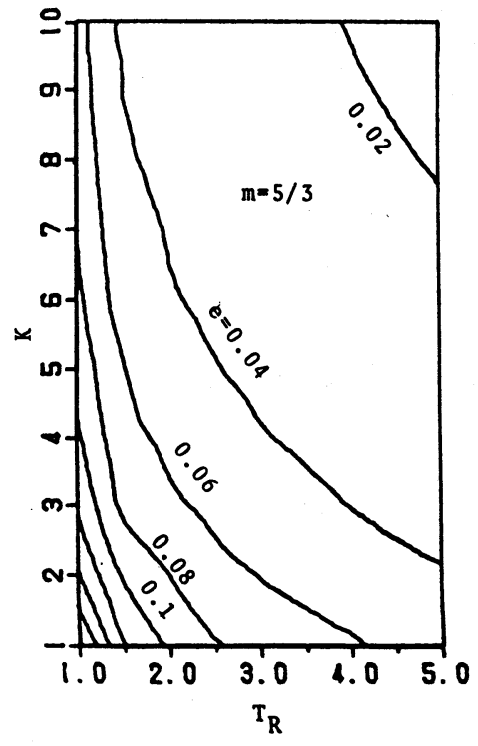

図4 単-喓素 kinematic wave モデルの集中 化誤差の等値線図

$$
(m=5 / 3)
$$

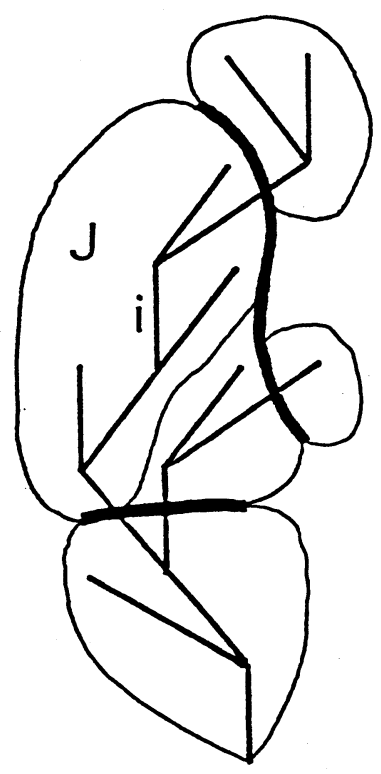

図 5 河道網の分割 
は kinematic wave 定数 $\mathrm{m}$ を一様とすれば,

$$
\begin{aligned}
& S_{i}=r_{0}^{1 / m} s_{i} \\
& s_{i}=(m /(m+1))\left(l_{i} / f_{i}\right)\left(1 / \alpha_{i}\right)^{1 / m}\left\{a_{i}^{(m+1) / m}-\left(a_{i}-f_{i}\right)^{(m+1) / m}\right\}
\end{aligned}
$$

で表される。ただし， $a_{i}$ は河道リンク $\mathrm{i}$ を含め河道リンク $\mathrm{i}$ の上流にある総ての河道リンクの集水面積 の和を表す。部分河道網 J 内の総ての河道リンクについて(11)式を加えれば, 部分河道網 J の貯水量

$$
S_{J}=\Sigma S_{i}=r_{0}{ }^{1 / m} \Sigma S_{i}
$$

が得られる。

一方, 河道網 $J$ の下流端点での定常時流量は， $Q_{J}=r_{0} a_{J *}$ である。ただし，J*壮部分河道網 J の 最下流の河道リンクの番号である。この式と (12)式から $r_{0}$ をを消去すれば，定常時の部分河道網の貯水量〜 流出量関係式

$$
Q_{\mathrm{J}}=\alpha_{\mathrm{J}} \mathrm{S}_{\mathrm{J}}^{\mathrm{m}}, \quad \alpha_{\mathrm{J}}=\mathrm{a}_{\mathrm{J} *} /\left(\Sigma_{\mathrm{S}_{\mathrm{i}}}\right)^{\mathrm{m}}
$$

が得られる。 $\alpha_{\mathrm{J}}$ は，集水域単位面積当たりの流出強度 $\mathrm{r}_{0}$ に依存しない定数である。

こうして，部分河道網への分割が与えられれば，元の kinematic wave モデルを集中化した多段眝水池モ デルが得られることになる。

\section{2 河道網の分割基準}

前項の集中化モデルを具体的に構成するためには，流域分割個数 N とその分割点を決める必要がある。 そこで，2章で述べた単一要素 kinematic wave モデルの集中化誤差構造に基づいた分割個数の決定方法と, 分割個数が決定された上での分割点の決定方法を述べる。

まず, 河道網系 kinematic wave モデルと単一要素 kinematic wave モデルとを対応させるために，次の ような地形パターン関数を用いた河道網系の統合2)モデルを考える。

$$
\begin{aligned}
& w=p(y)(1-m) \quad(\alpha / \ell) s^{m} \\
& \partial s / \partial t+\partial w / \partial y=p(y) r_{0}(t)\left(\Sigma f_{i} / \Sigma \ell_{i}\right)
\end{aligned}
$$

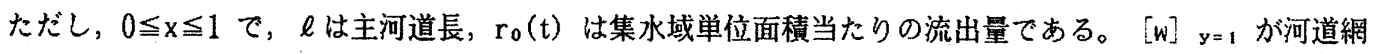
下流端の流出量である。ここで, 地形パターン関数 $\mathrm{p}(\mathrm{y})$ は $\mathrm{y}$ にらず一定であると仮定すると総河道長， つまり $\mathrm{p}(\mathrm{y})=\Sigma \ell_{\mathrm{i}}$ となり単一要素 kinematic wave モデル (1)式に帰着する。このとき，(2)式の $\mathrm{T}_{\mathrm{R}}$ は,

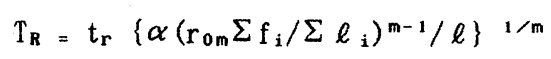

となる。ここで，rom は集水域単位面積当たりの平均流出 強度である。

一方, 河道流に対する単一要素 kinematic wave モデル の集中化誤差構造は，2 章で述べた方法により $\mathrm{m}=1.45$ とする4ことにより得られる。これを図6に示す。ただし， この図では斜面流の場合の図 4 と異なり，縦軸に集中化誤 差 $\mathrm{e}$ をっている。単一要素の区分個数は図中 $k$ で示す。 河道網については図 5 の太線で区切られる河道網の個数 を区分個数とよび，この区分個数を単一要素の区分個数に 対応させる。部分河道網の個数を分割個数とよぶことにす する。分割個数は区分個数より多くなることもある。

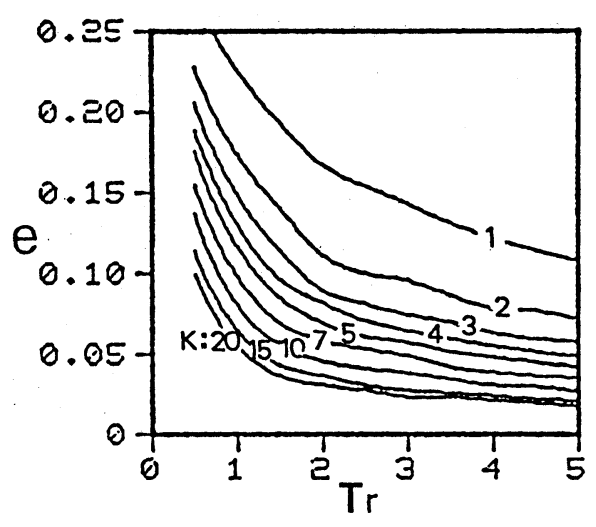

図6 単一要素モデルの集中化誤差 $(\mathrm{m}=1.45)$ 
図 5 の太線と河道リンクの交点，すなわち分割点の位置 は，分割点から分割点までの定常時伝播時間か，河道網の 最上流端から最下流端までの伝播時間を区分個数 $\mathrm{k}$ で等分 した時間に等しくなるように下流の方から決めてゆく。た だし，支川の最上流端からその最上流分割点まての伝播時 間が $\mathrm{K}$ 等分した伝播時間の 7 割に淦たない場合は，その分 割点は設けない。これは，むやみに部分河道網の個数を多 くしないためである。

図 7 に，由良川水系荒倉流域 $\left(159 \mathrm{~km}^{2}\right)$ の荒倉地点 $(\times$ 印) とその中流地点( $\mathrm{O}$ 印)を下流端とする河道網について得ら れた集中化誤差 e と(16)式の $T_{R}$ との関係を $K=5,15$ について示す。図中害線は単一要素モデルでの関係で, 図 6 の $\mathrm{K}=5,15$ の線である。(16)式を媒介とした河道網の 集中化誤差構造は, 単一要素の場合の詿差構造によく対応 している。

したがって，河道網の区分個数 K は単一要素モデルの集 中化誤差構造に基づいて決定できると言える。すなわち, 対象とする河道網と入力の継続時間, 強度が与えられると (16)式により $\mathrm{T}_{\mathrm{R}}$ が決定されるので，図6を用いて許容さ れる集中化誤差 e に対する区分個数 K が定まる。K が定 まれば，前述の方法によって部分河道網への分割も決まる ことになる。
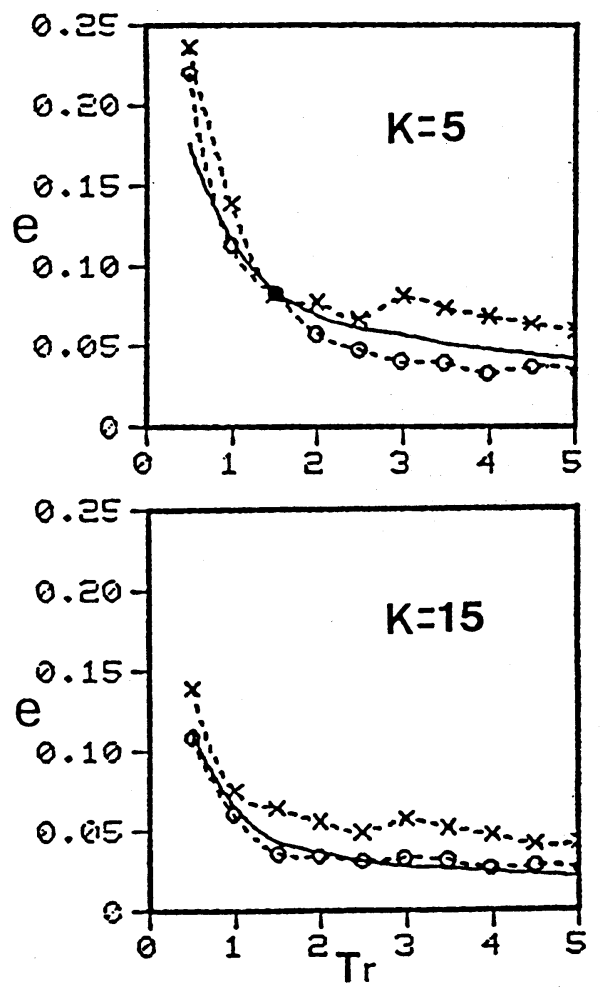

図 7 単一要素の集中化誤差と河道網 の集中化誤差との関係

\section{4. あとがき}

本研究では, 系の応答時間に相対的な入力の継続時間 $\mathrm{T}_{\mathrm{R}}$ が与えられれば, kinematic wave モデルを集 中化した多段貯水池モデルの貯水池個数が決定できることを示した。ただし，入力の時間配分パターンを二 等辺三角形のものに限って検討した。流出量の時間的変化はもちろん入力の時間配分パターンに依存するが， 集中化の程度，すなわち，多段眝水池モデルの貯水池個数を入力の時間配分パターンによって大きく変化さ せる必要はないと予想される（この点に関する检討が残されている）。

\section{参考文献}

1) 椎葉・高棹 : 単一要素 Kinematic wave モデルの集中化について, 土木学会第37回年講 II -337, 1982

2）高棹・椎葉：Kinematic Wave 法への集水勃果の導入，京大防災研究所年報，第24号B-2,1981

3）中北・高棹・椎葉 : 河道網系 Kinematic wave モデルの集中化，土木学会第39回年講 II-337, 1984

4）上田 : 降雨流出に関する研究, 九州大学学位論文, 1961 